\title{
PARTICIPAÇÃO SOCIAL NOS CONSELHOS DE UNIDADES DE SAÚDE
}

Eliane Patricia Lino Pereira Franchi ${ }^{1}$, Micheli da Silveira Galvani ${ }^{2}$, Rosangela de Castro Rezende Pereira ${ }^{3}$, Wilza Carla Spiri ${ }^{4}$

RESUMO: Estudo exploratório e qualitativo buscou compreender como ocorre a participação dos usuários nos Conselhos de Unidades de Saúde do Município de Botucatu-São Paulo. Os dados foram coletados de setembro a outubro de 2008 por meio de entrevista orientada por roteiro semiestruturado a nove usuários, membros do Conselho de quatro unidades básicas de saúde. Após análise de conteúdo surgiram três categorias temáticas: Conhecendo o usuário/conselheiro, O Conselho de Unidades de Saúde e A participação no Conselho. Os resultados mostram despreparo e falta de conhecimento dos conselheiros representantes dos usuários sobre o papel dos Conselhos e políticas públicas de saúde, evidenciando a necessidade de que os atores dos serviços de saúde invistam na orientação, conscientização e preparo de cidadãos com capacidade crítica para influenciar, direcionar, reivindicar e questionar as ações dos serviços de saúde.

PALAVRAS CHAVE: Participação comunitária; Conselhos de saúde; Saúde pública.

\section{SOCIAL PARTICIPATION IN THE COUNCILS OF HEALTH CENTERS}

ABSTRACT: This exploratory and qualitative study sought to investigate how health service users' participation on the Councils of Health centers occurs in the municipality of Botucatu in São Paulo. Data was collected in September and October 2008 via interviews guided by a semi-structured script, administered to 9 service users who are members of the Council at four primary health care centers. After content analysis, three thematic categories emerged: Knowing the service user/councillor, The Health Centers' Council and Participation on the Council. The results show the unpreparedness and lack of knowledge of the councillors representing health service users on the subject of the role of the Councils and on public health policies, evidencing the need for actors from the health services to invest in guidance, consciousness-raising and preparation of citizens with critical ability to influence, guide, demand and question the health services' actions.

KEYWORDS: Community participation; Health councils; Public health.

\section{PARTICIPACIÓN SOCIAL EN LOS CONSEJOS DE UNIDADES DE SALUD}

RESUMEN: Estudio exploratorio y cualitativo que buscó comprender cómo ocurre la participación de los usuarios en los Consejos de Unidades de Salud del municipio de Botucatu - São Paulo. Los datos fueron obtenidos de septiembre a octubre de 2008 por medio de entrevista orientada por guión semiestructurado a 9 usuarios, miembros del Consejo de cuatro unidades básicas de salud. Después del análisis de contenido, surgieron tres categorías temáticas: Conociendo el usuario/consejero, El Consejo de Unidades de Saludy La participación en el Consejo. Los resultados muestran falta de preparación y de conocimiento de los consejeros representantes de los usuarios sobre el papel de los Consejos y políticas públicas de salud, evidenciando la necesidad de que los actores de los servicios de salud inviertan en la orientación, conscientización y preparación de ciudadanos con capacidad crítica para influenciar, conducir, reivindicar y cuestionar las acciones de los servicios de salud.

PALABRAS CLAVE: Participación comunitaria; Consejos de salud; Salud pública.

\footnotetext{
${ }^{1}$ Enfermeira. Mestre em Doenças Tropicais. Doutoranda em Doenças Tropicais pela Universidade Estadual Paulista - UNESP.

${ }^{2}$ Enfermeira da Estratégia Saúde da Família da Secretaria Municipal de Saúde de Tanabi - SP.

${ }^{3}$ Enfermeira da Secretaria Municipal de Saúde de Piracicaba - SP.

${ }^{4}$ Enfermeira. Doutora em Enfermagem. Professora do Departamento de Enfermagem da UNESP.
}

Autor correspondente:

Eliane Patricia Lino Pereira Franchi

Universidade Estadual Paulista

Rua Dr. João Queiroz Reis, 868 - 18607-010 - Botucatu-SP-Brasil

E-mail: fliane24@gmail.com
Recebido: $14 / 05 / 2012$

Aprovado: 30/07/2012

Cogitare Enferm. 2012 Out/Dez; 17(4):690-6 


\section{INTRODUÇÃO}

O Sistema Único de Saúde (SUS), criado a partir da Constituição de 1988 e regulamentado em 1990 pelas Leis 8.080 e 8.142 , decorreu do processo político que mobilizou a sociedade brasileira e propôs novos modelos de organização do sistema, serviços e práticas de saúde. Essas mudanças ditam a organização do SUS que é baseada nos princípios da universalidade, equidade e integralidade da assistência à saúde, assim como na participação social na gestão do sistema de saúde nas diferentes esferas de governo ${ }^{(1-3)}$.

O despertar do interesse pela participação social corresponde às alterações ocorridas na relação Estado/ sociedade, associado ao movimento geral brasileiro na década de 1980, em que as propostas de democratização adquiriram novas proporções. Buscou-se, desta forma, suprimir as formas autoritárias e tradicionais de gestão das Políticas Sociais, bem como a adoção de práticas que viabilizem a transparência das informações e aumentem a participação social no processo decisório ${ }^{(4)}$.

Com a promulgação da Lei n. 8.142, de 1990, os conselhos de saúde, juntamente com as conferências de saúde, passaram a ocupar a condição de instância formal de exercício do princípio de participação social. Os conselhos de saúde são definidos como organismos colegiados de caráter deliberativo e permanente, compostos por representantes do governo, prestadores de serviços, profissionais de saúde e usuários, sendo que a representação dos usuários se dá de forma paritária em relação aos demais segmentos ${ }^{(3)}$. As conferências e conselhos de saúde estão presentes nas três esferas de governo: nacional, estadual e municipal.

No âmbito municipal, além do Conselho Municipal de Saúde (CMS), podem-se ter os Conselhos de Unidade de Saúde (CONUS). Em Botucatu, a primeira Conferência Municipal de Saúde, realizada em 1992, regulamentou a criação dos CONUS Este tem como objetivo identificar e resolver os problemas de saúde em nível local, na abrangência de cada unidade básica de saúde (UBS). A atuação desses conselhos deve extrapolar as UBS, e se estender pelos bairros, escolas, igrejas, centros comunitários, indústrias, projetos sociais, discutindo e identificando questões que influenciam a saúde da população(5).

O CONUS deve ser formado por representantes dos profissionais de saúde (25\%), da administração (25\%) e dos usuários das UBS (50\%). Dentre os conselheiros, a parte composta pela população tem lugar de destaque, pois é o usuário do SUS que vivencia e conhece as reais deficiências do seu meio.
Neste contexto, este estudo tem o objetivo de compreender como ocorre a participação dos usuários nos CONUS de Botucatu-São Paulo, o que se justifica pela importância de revelar como os usuários atuam neste Conselho, e se estes comportam-se como espaço de exercício concreto do controle social em saúde.

\section{MÉTODO}

Trata-se de um estudo exploratório de abordagem qualitativa que seguiu os princípios da análise de conteúdo ${ }^{(6)}$. A pesquisa foi realizada na cidade de Botucatu, localizada na região centro sul do Estado de São Paulo, que tem aproximadamente 127.328 habitantes $^{(7)}$, e uma rede de atenção básica constituída de 18 UBS. Dentre essas unidades, quatro possuem CONUS, três são Unidades Estratégias de Saúde da Família e um Centro de Saúde pertencente à Faculdade de Medicina de Botucatu, da Universidade Estadual Paulista (UNESP), e um total de 13 conselheirros usuários.

Foram excluídos do estudo quatro conselheiros usuários não localizados no período de pesquisa. Logo, participaram 9 conselheiros representantes dos usuários nas UBS citadas. A coleta de dados ocorreu nos meses de setembro e outubro de 2008.

Os dados foram obtidos por meio de entrevista semiestruturada e áudio gravada para facilitar a apreensão do conteúdo das falas, que foram transcritas. Os conselheiros foram abordados no final da reunião do CONUS e informados sobre os objetivos e desenvolvimento da pesquisa. Após a assinatura do Termo de Consentimento Livre Esclarecido, os participantes foram entrevistados individualmente. Aqueles que faltaram à reunião foram procurados em seu endereço residencial. Em duas UBS as reuniões não vinham acontecendo devido à ausência dos conselheiros. Diante disso, os responsáveis pelas unidades disponibilizaram o endereço dos conselheiros para comunicação. Conseguiu-se contatar um conselheiro de cada uma dessas unidades.

Após a transcrição dos dados, foi realizada análise a partir da leitura exaustiva das falas, das quais se buscou extrair informações relevantes por meio de repetições, tendências ou divergência. Desta forma, foram construídas três categorias de análise temática: Conhecendo o usuário/conselheiro, O Conselho de Unidades de Saúde e A participação no Conselho.

Os dados foram coletados após autorização pelo Comitê de Ética em Pesquisa da UNESP (Protocolo Of.452/08-CEP) e concordância dos sujeitos, conforme estabelecido pela Resolução 196/96 do Conselho Nacional de Saúde. 


\section{RESULTADOS}

\section{Conhecendo os usuários/conselheiros}

Dos 9 conselheiros, três $(33,3 \%)$ são mulheres e seis $(66,7 \%)$ homens com faixa etária de 35 a 70 anos, sendo 7 (77,7\%) deles com mais de 56 anos. Em relação à formação, quatro $(44,4 \%)$ entrevistados relataram 13 anos de estudo e cinco $(55,6 \%) 8$ anos ou menos.

A maioria dos representantes não relatou ocupação definida, sendo que 7 (77,7\%) participantes definiram-se, simultaneamente, como aposentados ou do lar, um $(11,1 \%)$ cabeleireiro e um $(11,1 \%)$ auxiliar de serviços gerais. Dentre todos os entrevistados, um referiu não ser usuário do SUS.

Todos conselheiros referiram frequentar agremiações externas ao Conselho, sendo as mais citadas a participação em igrejas e pastorais, seguida por grupos de terceira idade, associações de bairro e conselho do idoso. Todavia, todos negaram divulgar o CONUS nestes lugares, como demonstrado na fala a seguir:

Você me levantou um problema que eu não tinha pensado, eu poderia muito bem estar levando esses problemas, esses assuntos, para as reuniões do CMPP, que é o Conselho Missionário Pastoral da Paróquia. (Conselheiro 2)

Dos conselheiros entrevistados, quatro referiram estar no segundo mandato, e um no terceiro mandato, sendo que destes, alguns já participaram como conselheiros do CONUS em outras unidades de saúde ou do Conselho Municipal de Saúde. Um dos conselheiros referiu que a atuação desse conselho é mais ativa e diferente de sua outra experiência, outro relata que as pessoas são mais interessadas e não faltam aos encontros, de acordo com as falas:

Dois mandatos lá no CSE, e aqui é o primeiro. Sempre tô participando porque eu acredito que nós precisamos fazer. Não adianta nada ficar reclamando. (Conselheiro 3)

A atuação do Conselho, dos profissionais do Conselho, é bem melhor do que o Conselho que eu participei [...] é muito mais ativo, o pessoal tá muito mais interessado, o pessoal não falta das reuniões. (Conselheiro 4)

\section{O Conselho de Unidade de Saúde}

As falas dos conselheiros relatam diversas maneiras pelas quais tomaram conhecimento da existência do Conselho. Dentre elas, a divulgação verbal e visual feita por funcionários da UBS e membros do CONUS. Houve um entrevistado que relatou ser convidado por integrantes do grupo da terceira idade, que frequentavam o Conselho. Os recortes das falas ilustram:

O pessoal do posto me convidou, não tinha conhecimento disso daqui, do CONUS, eu não tinha conhecimento de nada. (Conselheiro 1)

Tava esperando a consulta e vi um cartaz falando do CONUS, das datas das reuniões. (Conselheiro 4)

Eu frequento a terceira idade, né? Então, tem um pessoal lá que vai no Conselho. Então eles me convidaram e eu comecei a ir. (Conselheiro 5)

O primeiro contato com o conselho foi narrado como pouco participativo pelos entrevistados, que mencionaram o desconhecimento do CONUS e a timidez como fatores limitantes. Apesar dos percalços, revelam que a experiência foi positiva e estimulante Segundo os conselheiros, a participação no CONUS influenciou positivamente em suas vidas, embora a maioria não tenha especificado que tipo de mudança ocorreu. Aqueles que mencionaram, relataram alterações nas relações interpessoais, e a própria conduta diante dos fatos, desenvolvendo a capacidade crítica. As falas a seguir ilustram estas percepções:

[...] a principio, não entendi nada. Ai falei: 'Vou entrar porque dai eu vou aprender melhor'. Peguei, teve a eleição, a gente foi eleito pela comunidade. (Conselheiro 2)

Tinha receio de chegar em certas pessoas, de certos cargos que agora eu já não tenho mais [...]. Então, eu acho que me liberou um pouco mais. (Conselheiro 7)

Foi questionada a ocorrência de transformações no exercício da cidadania após a entrada no Conselho. A maioria relata que o CONUS despertou o interesse por questões ligadas a essa temática, embora não tenham especificado; apenas um entrevistado apresentou argumento diante da afirmação e outro relatou não ter ocorrido qualquer tipo de mudança neste aspecto:

[...] a gente acaba engajando mais e tentando procurar, tentando saber como que tá a população, algumas coisas que dá prá gente ajudar. (Conselheiro 9) 
[...] acredito que não mudou muita coisa. Não tenho tempo, trabalho muito. (Conselheiro 6)

As declarações demonstram valorização dos assuntos relacionados às políticas de saúde. Mencionam a importância de buscar o saber sobre as políticas de saúde e reivindicar seus direitos.

Ah sim, porque dai a gente vai ficando sabendo das coisas, dai a gente quer aprender mais, quer participar mais. É muito bom. Eu vejo se as pessoas são bem atendidas. (Conselheiro 4)

\section{A participação no Conselho}

Os conselheiros julgaram-se importantes e atuantes dentro do CONUS. Somente um entrevistado negou ser, de fato, ativo:

Eu me considero importante. Eu não perco reunião! Eu deixo meus afazeres e venho aqui. (Conselheiro 4)

Minha participação agora tá meio fraquinha porque eu tô com muitas coisas prá fazer, então aí ficou difícil. Até nas últimas reuniões, não deu prá mim ir. (Conselheiro 6)

Em geral, os participantes afirmaram existir cooperação e não haver conflitos entre os integrantes do conselho, ou deste com outros segmentos sociais. Apenas um relato diferenciou-se do restante, enfatizando a falta de comunicação entre membros do CONUS:

Não, desde quando eu entrei aqui até hoje, eu não presenciei conflito nenhum. Sempre agimos, procuramos agir em comum acordo. (Conselheiro 8)

O povo do Conselho não gosta de se comunicar. Sinto meio retraido, né. (Conselheiro 7)

Houve divisão de opiniões quando interrogado sobre o funcionamento da participação social dentro das políticas e ações de saúde. Os conselheiros das UBS com Conselho ativo acreditam na participação social, enquanto que aqueles das unidades não atuantes avaliam que isso não ocorre na prática, como ilustrado abaixo:

O pessoal vem uma vez, gosta, então continua participando. (Conselheiro 5)
A população pede, critica, mas na hora que é pra ir lá, ela não vai. A gente conversa com eles, pede pra ir na reunião, às vezes vem falar as coisas e a gente fala: 'vocês também têm que ir lá pra expor pra todo mundo!' Só que chega na hora, eles não vão [...]. A população não participa. (Conselheiro 2)

Segundo alguns entrevistados, a população reclama muito, mas não quer participar das reuniões do Conselho. Referem que os profissionais das UBS se empenham na divulgação e mobilização da população para participar do Conselho, manifestando por meio de cartazes, convite verbal em sala de espera, informes na rádio, distribuição de panfletos pelos agentes comunitários e festa de divulgação. Porém, é pequeno o interesse da comunidade pelo CONUS, como exemplicado:

Sempre tem aquelas pessoas que falam mal, mas na hora que você chega perto dele prá falar 'vamos lá resolver então o problema', dai o pessoal diz 'ah não, deixa pra lá. Fizemos a festinha aqui, chamamos o pessoal e não apareceu ninguém que queria participar da reunião. (Conselheiro 2)

Apesar das dificuldades enfrentadas para manter o Conselho atuante, todos consideram que houve melhora na assistência à saúde depois da ação do CONUS. Em geral, os sujeitos afirmam haver certa influência do Conselho frente os gestores e representações políticas, dependendo da reivindicação que é feita

Conseguimos várias coisas através dos Conselhos. Como a gente tem a caixinha de sugestões, ficamos sabendo, nessa caixinha vêm as sugestões, vem a boa, vem a ruim, vem agradecendo, outras não, mas tudo faz parte. (Conselheiro 5)

[...] já brigamos até com o Secretário da Saúde [...]. Já teve uma briga lá, fizemos um documento, fomos todo mundo lá [...]. Ele ficou muito bravo, quase brigou com a gente, lá. Não tínhamos muito apoio da Secretaria de Saúde. A gente fazia reclamação, mas eles não tinham boa disposição de ver a necessidade da população. (Conselheiro 3)

Apenas um dos entrevistados negou ter influência a atuação do Conselho:

[...] não tem influência não. Semana passada perguntei pro doutor se o conselho seria soberano, certo? E ele 
disse que agimos junto, em comum acordo, e que nem ele, nem nós somos soberanos. (Conselheiro 02)

\section{DISCUSSÃO}

O Município de Botucatu é distinto por apresentar em seu cenário de saúde a atuação dos CONUS. A literatura é escassa de estudos realizados com esta categoria de conselho, sendo a maior parte destes realizados com CMS. O perfil dos conselheiros deste estudo é similar ao encontrado em $2009^{(5)}$, com entrevistados em uma faixa etária de 43 a 66 anos, maioria homens, aposentados, e escolaridade igual ou menor ao $2^{\circ}$ grau completo.

A baixa escolaridade dos participante é um dos fatores que sugere esclarecer a deficiência encontrada no conhecimento das diretrizes e políticas de saúde. Entende-se que a educação influencie diretamente na qualidade da participação do conselheiro, já que para desenvolver a cidadania, estudar é fundamental, porque amplia o entendimento e envolvimento das pessoas sobre as coisas e o mundo ${ }^{(8)}$.

Para o fortalecimento do controle social torna-se necessário o desenvolvimento de práticas democráticas na sociedade, já que a participação não é um conteúdo que pode ser transmitido, mas um conceito e comportamento a serem construídos pela reflexão crítica e amadurecimento do cidadão ${ }^{(9)}$. A representação no conselho demanda ações de mobilização e recrutamento de indivíduos para o exercício da cidadania. Entretanto, nesta pesquisa, os entrevistados relatam não abordarem assuntos inerentes ao CONUS em outros locais.

De todos os participantes, um relatou não ser usuário do SUS e que, portanto, não vivencia as necessidades dos usuários, os quais representa. Isso evidencia a preocupação em apenas cumprir com um número adequado de representantes, desconsiderando o verdadeiro papel do representante nos conselhos. Dessa forma, o CONUS perde a ideologia do controle social, anulando a participação do usuário. Tais evidências demonstram que apenas a existência formal dos espaços de controle social não assegura a participação política da sociedade, tornando esses espaços um local de atendimento a uma formalidade legal do sistema. Esses problemas afetam diretamente a eficácia dos conselhos locais $^{(10)}$.

Constatou-se nas entrevistas que a forma de divulgação predominante das reuniões do Conselho é a informal, por meio de convites verbais dentro e fora da unidade de saúde. Porém, essa apresentação é superficial, não havendo a preocupação em informar os usuários sobre a dinâmica de funcionamento do CONUS, bem como seus objetivos e a importância de uma participação consistente da população no mesmo.

Houve influência positiva no desenvolvimento pessoal dos entrevistados depois do envolvimento com o CONUS, de acordo com seus relatos. Eles referem desinibição nas relações interpessoais e o desenvolvimento da capacidade de adotar condutas diante de fatos. O mesmo foi constatado em estudo realizado com conselheiros da região metropolitana do Rio de Janeiro, que especificou $72 \%$ de influência no plano cultural; $50 \%$ no profissional; $48 \%$ no familiar e $42 \%$ no escolar; $78 \%$ no social e comunitário e $70 \%$ no político ${ }^{(11)}$.

Acredita-se que o Conselho desperte nos indivíduos maior interesse pelas questões ligadas ao exercício da cidadania e políticas de saúde, sendo assim, os sujeitos foram questionados sobre a veracidade desta afirmação, e todos concordaram com esta contribuição. Cabe ressaltar que os conselheiros expuseram respostas superficiais e confusas sobre o tema. Isso sugere que o conceito de cidadania, e de como exercê-la, ainda encontra-se pouco fundamentado.

Algumas falas revelam a discordância da percepção dos pesquisadores que acompanharam as reuniões. Embora tenham se considerado atuantes, participando dos encontros e contribuindo com o andamento do CONUS, os representantes dos usuários não debatiam ou abordavam assuntos relevantes. As reuniões simulavam uma prestação de contas da UBS para com os representantes. Por exemplo: número de atendimentos médicos, de enfermagem e odontológicos durante o mês; cobertura vacinal durante campanha, entre outros. Esses dados quase não foram cobrados pelos usuários, e sim fornecido espontaneamente pela unidade.

Ocupar um cargo de conselheiro exige, ao menos, preparação e capacitação, mas o que se observa é uma deficiência de informações sobre o exercício da cidadania e/ou políticas de saúde do SUS. Consequentemente, muitos dos participantes não visualizam a importância de seu cargo e de suas responsabilidades para com os usuários do serviço. E, mais uma vez, o CONUS perde o sentido de existir, pois a prática do controle social não está sendo efetiva.

Os conselheiros demonstram-se satisfeitos com a contribuição do CONUS na melhoria na assistência à saúde, e associam esse avanço ao aumento do número de medicamentos fornecidos, novos equipamentos, contratação de profissionais, aumento de atendimentos, entre outros. Enfim, tal relação demonstra a crença 
de que a assistência se resume apenas em números, desconsiderando a qualidade da mesma. Essa definição inadequada da assistência à saúde pode camuflar a realidade dos indicadores de saúde.

Os usuários conselheiros acreditam que a influência sobre os gestores ocorre, discordando de outros achados $^{(9)}$. Em pesquisa realizada com o CMS de Botucatu, em 2006, a autora observou que os membros do Conselho, representantes dos usuários, embora estivessem presentes em praticamente todas as reuniões, quase nunca se manifestavam para concordar ou discordar dos assuntos em debate, propor ou encaminhar queixas ou sugestões da comunidade que representavam $^{(12)}$.

Verificou-se insuficiente conhecimento dos entrevistados sobre as diretrizes que regem a criação e o funcionamento do CONUS, o que resulta em uma baixa adesão desses nos processos decisórios. Falha talvez explicada pela carência de divulgação das atividades e das iniciativas do conselho para a população ${ }^{(10)}$.

Embora a legislação brasileira identifique os Conselhos de Saúde como ferramenta para validar os direitos dos cidadãos, vários estudos têm demonstrado que, em muitos municípios, suas diretrizes não são respeitadas, e tem como principal deficiência a falta de conhecimento dos conselheiros ${ }^{(5,9-11,13)}$. Esta deficiência pode ser utilizada por alguns gestores e autoridades públicas como pretexto para reforçar a imagem de que os representantes dos usuários são técnica e socialmente despreparados para perceberem, com clareza, a lógica de funcionamento e as necessidades do sistema de saúde. Justificam, assim, a atuação dos gestores no controle das atividades do Conselho. Como consequência, os Conselhos acabam tornando-se instâncias que apenas aprovam as decisões do gestor ${ }^{(9-10)}$.

A dificuldade da população em participar do CONUS fica mais evidente ao se observar as informações fornecidas na última questão da entrevista. Quando questionados sobre suas percepções em relação à existência do controle social na prática, os conselheiros relatam o desinteresse da população em participar, provavelmente causado pela falta de conhecimento sobre os objetivos e funcionalidade do CONUS ${ }^{(13)}$.

Esses achados concordam com estudo no qual $59,4 \%$ dos conselheiros relataram que a participação popular não ocorria no município estudado. As justificativas foram: o desinteresse e a desinformação da população, e a impossibilidade de exercer a participação popular naquele conselho..$^{(9)}$

Em estudo que avalia o grau de satisfação dos usuários do SUS, 44\% se dizem insatisfeitos e apenas $4 \%$ de satisfeitos com a prestação dos serviços públicos de saúde, sendo que $71 \%$ dos entrevistados referiram que se aborrecem quando procuram atendimento pelo SUS ${ }^{(14)}$. Isto evidencia o desconhecimento de seu papel na construção do SUS, e expõe a necessidade de construir mecanismos que possibilitem à população perceber a importância da participação popular e da inserção no controle social.

\section{CONSIDERAÇÕES FINAIS}

De todas as unidades do município pesquisado, apenas quatro possuem CONUS. Destas quatro unidades, identificou-se que as reuniões não aconteciam há mais de dois meses em duas das unidades, evidenciando-se, a dificuldade na prática do controle social defendida pela política do SUS.

Apesar do grande avanço que houve na história da sociedade moderna, principalmente no que tange às políticas públicas de saúde mediante a formulação do SUS, que prega princípios como integralidade, equidade, universalidade e controle social, pode-se observar que pouco se avançou nesse aspecto. Embora uma iniciativa em promover a participação social, a implantação dos Conselhos de Saúde, a efetividade da participação social, como observado nos CONUS em Botucatu, ainda é superficial e de pouco impacto nas deliberações do gestor.

Esta condição se deve, principalmente, ao despreparo dos conselheiros que, embora estivessem presentes nas reuniões, pouco se manifestavam, e quando isso ocorria não era de forma consistente. Observou-se carência de conteúdo relacionado ao papel dos conselheiros, ao significado do CONUS, ao conceito de cidadania e ao funcionamento das políticas públicas de saúde. Constatou-se também que poucos são os esforços dos atores dos serviços de saúde em orientar, conscientizar e preparar cidadãos com capacidade crítica para influenciar, direcionar, reivindicar e questionar as ações dos serviços de saúde.

Contudo, permanece a necessidade de reivindicação por parte dos cidadãos pela proteção dos direitos econômicos, sociais, políticos e culturais e, sobretudo, deve se propor que estes direitos sejam partes integrantes da vida dos indivíduos. Discutir a exclusão social "típica" da cidadania parece ser um dos elementos cruciais para a ampliação dos debates sobre a atuação dos Conselhos de Saúde, inclusive do CONUS. A colocação deste tema pode ter implicações decisivas nas atitudes dos atores 
envolvidos, concorrendo, por exemplo, para minimizar os riscos de utilização pré-meditada e indevida do controle social por gestores e políticos, com o intuito puro e simples do exercício do poder.

Não se espera desmerecer os Conselhos de Saúde, ao contrário, o estudo demonstra a urgência em construí-los como um espaço de democracia e debate. Não cabe às autoras determinar como isso será feito, embora tenha sido identificada a necessidade de educação para a cidadania. Talvez esse seja o marco da mudança, a educação.

\section{REFERÊNCIAS}

1. Brasil. Constituição da República Federativa do Brasil de 1988, com as alterações adotadas pelas Emendas Constitucionais 1/92 a 44/2004 e pelas Emendas Constitucionais de Revisão n. 1 a 6/94. Brasília: Senado Federal, Subsecretaria de Edições Técnicas; 2004.

2. Brasil. Lei no 8080 de 19 de setembro de 1990. Dispõe sobre as condições para promoção, proteção e recuperação da saúde, a organização e o funcionamento dos serviços correspondentes e dá outras providências. Diário Oficial da República Federativa do Brasil, 1990.

3. Brasil. Lei n. 8.142 de 28 de Dezembro de 1990. Dispõe sobre a participação da comunidade no Sistema Único de Saúde (SUS) e sobre as transferências intergovernamentais de recursos financeiros na área da saúde e dá outras providências. Diário Oficial da República Federativa do Brasil, 11990.

4. Sposati A, Lobo E. Controle social e políticas de saúde. Cad. Saúde Pública. [Internet] 1992;8(4) [acesso em 12 nov 2012]. Disponível: http://www.scielo.br/pdf/rk/ v10n1/v10n1a11.pdf

5. Ramos FT. Conselho de Unidade de Saúde (CONUS) do Município de Botucatu-SP: a percepção dos conselheiros [monografia]. Botucatu (SP): Universidade Estadual Paulista Júlio de Mesquita Filho; 2010.

6. Instituto Brasileiro de Geografia e Estatística [Internet] [acesso em 12 nov 2011]. Disponível: http://www.ibge. gov.br/cidadesat/topwindow.htm?1.

7. Bardin L. Análise de conteúdo. Edições 70. Lisboa; 2009.

8. Wendhausen ALP, Barbosa TM, Borba MC. Empoderamento e recursos para a participação em conselhos gestores. Saude soc. [Internet] 2006;15(3) [acesso em 12 nov 2012]. Disponível: http://www.scielo. br/pdf/sausoc/v15n3/11.pdf
9. Cotta RMM, Martins PC, Batista RS, Franceschinni SCC, Priore SE, Mendes FF. O controle social em cena: refletindo sobre a participação popular no contexto dos Conselhos de Saúde. Physis. [Internet] 2011;21(3) [acesso em 12 nov 2012]. Disponível: http://www.scielo.br/scielo.php?script=sci_ arttext\&pid=S0103-73312011000300019\&lng=en\&nrm $=$ iso $>$. ISSN 0103-7331.http://dx.doi.org/10.1590/S010373312011000300019 .

10. Martins PC, Cotta RMM, Mendes FF, Franceschinni SCC, Priore SE, Dias G, et al. Conselhos de saúde e a participação social no Brasil: matizes da utopia. Physis. [Internet] 2008;18(1) [acesso em 12 nov 2012]. Disponível: http://www.scielo.br/scielo.php?script=sci_ arttext\&pid=S0103-73312008000100007\&lng=en\&n $\mathrm{rm}=\mathrm{iso}>$. ISSN 0103-7331. http://dx.doi.org/10.1590/ S0103-73312008000100007.

11. Labra ME, Figueiredo JSA. Associativismo, participação e cultura cívica. O potencial dos conselhos de saúde. Ciênc. saude colet. [Internet] 2002;7(30) [acesso em 12 nov 2012]. Disponível: http://www.scielosp.org/pdf/csc/ v7n3/13030.pdf

12. Morita I, Guimarães JFC, Di Muzio BP. A participação de conselheiros municipais de saúde: solução que se transformou em problema? Saude soc. [Internet] 2006;15(1) [acesso em 12 nov 2012]. Disponível: http:// www.scielo.br/pdf/sausoc/v15n1/06.pdf

13. Silva LMS, Silva MRF, Lima LL, Fernandes MC, Oliveira NRN, Torres RAM. Análise da organização e funcionamento dos conselhos de saúde e a gestão participativa em Fortaleza, CE. Saude soc. [Internet] 2012;21(1) [acesso em 12 nov 2012]. Disponível: http://www.scielo.br/scielo.php?script=sci arttext\&pid=S0104-12902012000500010\&lng=en\&n rm=iso>. ISSN 0104-1290. http://dx.doi.org/10.1590/ S0104-12902012000500010.

14. Santos VC, Anjos KF, Costa CNA. Percepção de usuários sobre a assistência prestada na saúde pública. Cogitare enferm. [Internet] 2011;16(1) [acesso em 12 nov 2012]. Disponível: http://bases.bireme.br/cgi-bin/ wxislind.exe/iah/online/?IsisScript $=$ iah/iah.xis\&src= google\&base $=$ BDENF\&lang $=$ p\&nextAction $=\operatorname{lnk} \&$ ex prSearch=20476\&indexSearch=ID

Cogitare Enferm. 2012 Out/Dez; 17(4):690-6 